\title{
Percurso de implantação do terceiro ciclo para aprendizagem na rede pública de ensino do Distrito Federal
}

\section{Implementation of the 3rd cycle for learning in the public school system in the Federal District}

\section{Implementación del tercer ciclo de aprendizaje en el sistema escolar público del Distrito Federal}

\author{
Valdivina Alves Ferreira ${ }^{1}$ \\ Alisson Moura Chagas² \\ Thamara Maria de Souza²
}

DOI: http://dx.doi.org/10.20435/serie-estudos.v26i57.1306

\begin{abstract}
Resumo: O texto objetiva refletir acerca dos Ciclos para as Aprendizagens implementados na rede pública de ensino do Distrito Federal, legitimados pela Lei n. 5.499, de 14/7/2015, que aprova o Plano Distrital de Educação (PDE). Assim, a partir da promulgação do PDE (2015), as escolas, em substituição à organização seriada, passam a se organizar em ciclos para as aprendizagens. É uma pesquisa bibliográfica e documental. Mesmo com os aspectos legais, compreende-se que esse processo de organização escolar deve ser implementado com cautela, uma vez que a legislação é base dessa política pública, porém as leis não a sustentam por si só. Os dados analisados indicam a preocupação com a retenção dos estudantes, bem como a formação continuada para atuarem nos ciclos. Observa-se que não basta trocar a forma de organização da escolaridade, é preciso instrumentalizar os docentes para que possam materializar a política nas salas de aula.
\end{abstract}

Palavras-chave: organização do ensino; ciclo para as aprendizagens; professores.

Abstract: The text aims to reflect on the Learning Cycles in Law n. 5.499, of 7/14/2015, which approves the District Education Plan (PDE). Thus, from the promulgation of the PDE (2015), schools, replacing the serial organization, start to organize themselves in cycles for learning. It is a bibliographical and documentary research. Even with the legal aspects, it is understood that this process of school organization should be implemented with caution since the legislation is the basis of this public policy, but the laws do not support it by themselves. The analyzed data indicate the concern with the retention of the students, as well as the continuous formation to act in the cycles. It is observed that it is not enough to change the organization of schooling, it

\footnotetext{
${ }^{1}$ Universidade Católica de Brasília (UCB), Brasília, Distrito Federal, Brasil.

${ }^{2}$ Secretaria de Estado de Educação do Distrito Federal (SEEDF), Brasília, Distrito Federal, Brasil.
} 
is necessary to instruct the teachers so that they can materialize the politics in the classrooms.

Keywords: teaching organization; learning cycle; teacher.

Resumen: El texto tiene como objetivo reflejar los Ciclos de Aprendizaje implementados en el sistema de escuelas públicas del Distrito Federal, legitimados por la ley n. 5.499, del 14/07/2015, que aprueba el Plan de Educación Distrital (PDE). Así, luego de la promulgación del PDE (2015), las escuelas, en lugar de la organización serial, comenzaron a organizarse en ciclos de aprendizaje. Es una investigación bibliográfica y documental. Incluso con los aspectos legales, se entiende que este proceso de organización escolar debe ser implementado con cautela, ya que la legislación es la base de esta política pública, sin embargo, las leyes no la sustentan por sí sola. Los datos analizados indican la preocupación por la retención de los estudiantes, así como la formación continua para trabajar en los ciclos. Se observa que no basta cambiar la forma de organización de la escolarización, es necesario equipar a los docentes para que puedan materializar la política en las aulas.

Palabras clave: organización docente; ciclo de aprendizaje; maestros.

\section{INTRODUÇÃO}

A organização seriada sempre foi majoritária no Brasil, assim os processos de ensino vinculados a essa organização estão inseridos, possivelmente, em todos os sistemas de ensino, visto que até o século passado era assim que grande parte das escolas e/ou sistemas de ensino organizavam a escolaridade. Com isso, justifica-se a familiaridade dos docentes em trabalhar com essa forma de organizar a escolaridade. Porém os estudos de Ribeiro (2016) apontam que essa forma de organização é seletiva e excludente, visto que nem todos os estudantes conseguem concluir os estudos com êxito.

A necessidade de formação dos profissionais da educação para trabalhar com os Ciclos para as Aprendizagens, sobretudo os docentes que estão atuando em sala, é um dos elementos fundamentais dessa forma de organização, assim, "a Organização do Trabalho Pedagógico da escola e da aula tem como foco o processo de ensino e aprendizagem dos estudantes, sendo a coordenação pedagógica o espaço primordial dessa construção" (BRASÍLIA, DF, 2016, p. 14).

Este texto é um recorte de uma pesquisa maior, a qual analisou o processo de implementação do 3 ㅇ Ciclo para as Aprendizagens que representa parcialmente a realidade dos Centros de Ensino Fundamental (CEFs) da rede distrital, limitando-se as concepções docentes desse processo de implementação dos Ciclos na Rede Pública do Distrito Federal. Entende-se que a organização em Ciclos para as Aprendizagens é uma alternativa democrática, pois respeita os ritmos de apren- 
dizagens dos estudantes, minimiza as retenções e o fracasso escolar, os quais são instrumentos de exclusão de uma parte da sociedade no processo de ensino e aprendizagem. Contudo precisa ser implementada com cautela.

Este trabalho decorre de um estudo bibliográfico e documental que utiliza como suporte teórico os autores que pesquisam sobre organização escolar e tratam das formas de organização escolar em ciclos para as aprendizagens. Os fundamentos teóricos de Ribeiro (2016), Mainardes (2007), Libâneo, Oliveira e Toschi (2012), entre outros autores e documentos que referenciam a temática organização escolar e ciclos, comporão o quadro teórico e documental da pesquisa.

\section{ORGANIZAÇÃO ESCOLAR SERIADA E CICLADA: ASPECTOS HISTÓRICOS E LEGAIS}

A educação brasileira se organiza majoritariamente na forma seriada. De acordo com Ribeiro (2016, p. 79), “[...] a partir da década de 1890, com a criação dos grupos escolares, inicialmente em São Paulo, que o sistema seriado e o sistema de promoção de alunos de uma série para outra, de acordo com o nível de desempenho, se consolidaram no Brasil”. Para a autora, à época, esse sistema de organização era uma tendência dos países mais avançados e tornava-se um modelo de organização escolar a ser seguido mundialmente.

Ribeiro (2016), analisando a organização escolar seriada brasileira, mostra que "[...] as causas que dificultam o encaminhamento minimamente satisfatório dos problemas apresentados por essa organização vêm desde o início" (p. 79). Ainda em consonância com a autora, "[...] os problemas educacionais ao longo do tempo foram se agravando, muitos autores criticaram a escola seriada pela fragmentação e mecanização do trabalho dos docentes, individualização devido à competitividade entre educandos e ao desrespeito a vivência do indivíduo" (RIBEIRO, 2016, p. 83).

O regime seriado ao longo da história da educação brasileira tem produzido altas taxas de reprovação e evasão. Segundo Ribeiro (2016), diversos pesquisadores são favoráveis a romper com esse sistema majoritário de organização escolar, o qual é designado de excludente. "Tais estudiosos começaram a fazer menção a uma nova proposta de organização para o sistema educacional, denominada ciclo de aprendizagem" (RIBEIRO, 2016, p. 84). Segundo Mainardes (2007), a política pública da organização escolar em ciclos tem como objetivo reduzir essas taxas 
de reprovação; assim, entende-se que a organização escolar em ciclos é compreendida como menos seletiva e excludente.

A organização escolar em ciclos não é um termo que surgiu recentemente, o "termo 'escola em ciclos', como designação de políticas de 'não-reprovação', surgiu no Brasil com implementação do Ciclo Básico de Alfabetização (CBA) no Estado de São Paulo, em 1984" (MAINARDES, 2007, p. 11).

Para implementar uma política pública, como a organização da escolaridade em Ciclos para as Aprendizagens, é preciso investimentos "[...] na melhoria das condições de trabalho nas escolas e ainda mais professores, mais recursos didáticos e espaços" (MAINARDES, 2007, p. 16). A formação continuada dos docentes é o ponto de partida para resultados positivos da política de organização escolar em Ciclos para as Aprendizagens.

Para iniciar esse processo de implementação do 30 Ciclo para as Aprendizagens na Rede Pública de Ensino do Distrito Federal, o Conselho de Educação do Distrito Federal (CEDF), observando a Lei de Diretrizes e Bases da Educação Brasileira (LDB/1996), afirma que "A educação básica pode organizar-se em anos e séries anuais, períodos semestrais, ciclos, alternância regular de períodos de estudos e grupos não seriados, sempre que o interesse do processo de aprendizagem assim o recomendar" (CEDF, 2012, s.p.). Além disso, "[...] as diferentes etapas da educação básica e modalidades da educação são oferecidas em instituições educacionais credenciadas, de acordo com as normas do Sistema de Ensino do Distrito Federal" (CEDF, 2012).

Assim, "As instituições educacionais da Rede Pública de Ensino do Distrito Federal devem obedecer às normas e regulamentos da Secretaria de Estado de Educação do Distrito Federal" (CEDF, 2012). Ressalta-se que "É facultada às instituições educacionais da rede privada de ensino a adoção do Ciclo Sequencial de Alfabetização (CEDF, 2012). Desta forma, as instituições privadas de ensino do DF podem escolher outra forma de organizar os primeiros anos do ensino fundamental.

Ainda no que tange às normas que devem ser seguidas pelas instituições vinculadas à SEEDF, a Lei n. 3.483/2004, publicada no Diário Oficial do Distrito Federal (DODF) de 26 de novembro de 2004, antes mesmo da promulgação da lei n. 11.114, de 2005, já previa o Ensino Fundamental de 9 anos nas instituições da Rede Pública de Ensino do Distrito Federal (DF), que tinha duração mínima de 8 anos (BRASÍLIA, DF, 2004). 
Para atender essa estrutura do Ensino Fundamental, a SEEDF, a partir de 2005, passou a implementar o Bloco Inicial de Alfabetização (BIA) (BRASÍLIA, DF, 2014a), o qual transformava as três primeiras séries do Ensino Fundamental em um único bloco, que posteriormente seria designado primeiro bloco do 2 o Ciclo para as Aprendizagens. A partir de 2008, a implementação do BIA foi universalizada em todas as unidades escolares da rede distrital, o que estava em consonância com o artigo 25 da Resolução n. 1/2012 (CEDF, 2014).

Desta forma, esse primeiro bloco foi mencionado pelo CEDF no Art. 25 da Resolução 1/2012, reiterando a não retenção nos 1 e 2 anos do BIA, permitida a retenção apenas no término do primeiro bloco do 2 ㅇ Ciclo para as Aprendizagens, que equivale ao 3 o ano dos Anos Iniciais do Ensino Fundamental. Assim, no Ciclo Sequencial de Alfabetização, aos estudantes dos três primeiros anos no ensino fundamental, devem ser assegurados a alfabetização e o letramento, que são imprescindíveis para o prosseguimento dos estudos no segundo bloco do 2 - Ciclo para as Aprendizagens (CEDF, 2012).

Posta a situação do processo inicial de implementação dos Ciclos para as Aprendizagens, como a ampliação do Ensino Fundamental para 9 anos e formação do primeiro bloco de um ciclo, legislações posteriores a estas formam a base legal para a implementação desta forma de organização escolar na Rede Pública de Ensino do DF.

A lei n. 5.499/2015 aprova o Plano Distrital de Educação (PDE), o qual é compreendido como "[...] instrumento de planejamento, gestão e integração do sistema de ensino do Distrito Federal, construído com a participação da sociedade, para ser executado pelos gestores educacionais" (BRASíLIA, DF, 2015).

Em consonância com o Plano Nacional de Educação (PNE 2014-2024), no Plano Distrital de Educação (PDE 2015-2024), a meta 2 (dois), também, visa garantir "[...] o acesso universal, assegurando a permanência e a aprendizagem dos estudantes a partir dos 6 anos de idade, ao Ensino Fundamental de 9 anos, assegurando, também, a conclusão dessa etapa até os 14 anos de idade até o último ano de vigência deste Plano" (BRASÍLIA, DF, 2015).

A estratégia 2.3 do PDE (2015-2024) tem por objetivo a alteração da organização escolar do Ensino Fundamental na Rede Pública de Ensino do DF, que era preponderantemente seriada. Assim, a partir da promulgação do PDE, as escolas devem 
[...] adotar, após amplo debate com a comunidade escolar, até o terceiro ano de vigência deste Plano, modelo de organização escolar em ciclo, em substituição ao regime seriado, de modo a enfrentar os índices de reprovação e os percursos diferenciados de escolarização. (BRASíLIA, DF, 2015, s.p.).

O PDE (2015-2024) sinaliza a necessidade de um amplo debate com os envolvidos no processo de ensino e aprendizagem, ou seja, para implementar os Ciclos para as Aprendizagens, é necessário conscientizar tanto os estudantes, pais e comunidade local quanto os docentes. A necessidade de formação dos principais autores do processo de ensino e aprendizagem é ressaltada na estratégia 2.7 do PDE (2015-2024), que tem por objetivo “[...] implementar as diretrizes pedagógicas para os ciclos, assegurar a formação inicial e continuada dos professores e profissionais da educação" (BRASÍLIA, DF, 2015). Já a estratégia 2.35, também do PDE (2015-2024), visa

Fomentar ações pedagógicas que promovam a transição entre as etapas da educação básica e as fases do ensino fundamental e que gerem debates e avaliações entre os profissionais da educação sobre a organização escolar em ciclos e a organização do trabalho pedagógico, buscando melhorar a qualidade da educação. (BRASÍLIA, DF, 2015).

Assim, entende-se que a formação continuada auxilia qualitativamente a passagem dos estudantes em cada uma das etapas dos Ciclos para as Aprendizagens, e os docentes discutindo sobre a utilização da organização escolar em ciclos são instrumentalizados a ofertar uma educação de melhor qualidade. Libâneo, Oliveira e Toschi (2012) afirmam que, no campo educacional,

Existe um projeto de elevação da qualidade de ensino nos sistemas educativos com o objetivo de garantir as condições de promoção da competitividade, da eficiência e da produtividade demandada e exigidas pelo mercado. [...] trata-se de um critério mercadológico de ensino expresso no conceito de qualidade total. (LIBÂNEO; OLIVEIRA; TOSCHI, 2012, p. 126).

Segundo os autores, as secretarias de educação buscam a eficiência pedagógica por meio da implementação de projetos que visam à eficiência dos resultados, e esses projetos têm consequências, como a constante avaliação dos resultados que atestem a eficácia do trabalho pedagógico, bem como adesão a programas de gestão que visam à qualidade total. Sinalizam que a qualidade total é uma oposição à qualidade social. 
O processo de implementação dos Ciclos para as Aprendizagens na Secretaria de Estado e Educação do Distrito Federal iniciou-se antes da promulgação do PDE (2015-2024). O Conselho de Educação do Distrito Federal (CEDF), por meio do parecer n. 225/2013, aprovou o projeto de organização escolar em Ciclos para as Aprendizagens na Educação Infantil e Ensino Fundamental Anos Iniciais.

O primeiro Ciclo para as Aprendizagens corresponde à educação infantil, que atende crianças de creche ( 0 a 3 anos) e pré-escola (4 e 5 anos), e o segundo Ciclo para as Aprendizagens corresponde aos anos iniciais do ensino fundamental, também em dois blocos: o primeiro bloco, como já mencionado, corresponde ao BIA, e o segundo bloco abarca o 4o e 5ㅇa ano (BRASíLIA, DF, 2013a).

O parecer 225/2013 do CEDF aprovou o formato de verificação escolar que deve ser por meio da avaliação formativa, diagnóstica e contínua, que deu base legal à progressão continuada. O parecer aprovou, também, a forma de promoção

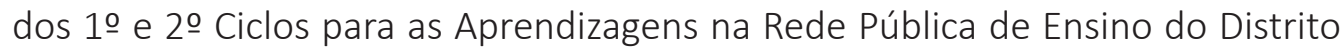
Federal.

Primeiro Ciclo: Sem retenção; Segundo Ciclo: Ensino Fundamental 1, sendo: 10 Bloco: Bloco Inicial de Alfabetização- BIA. O Processo de promoção escolar dos estudantes será concluído ao final do 3 o ano do Bloco, com possibilidade de retenção; $2^{\circ}$ Bloco: 4o e 5o anos. (BRASílIA, DF, 2013a).

O parecer 225/2013 do CEDF validou, ainda, todos os atos escolares do ano letivo de 2013, realizados pelas 245 instituições da Rede Pública de Ensino do DF que utilizaram a experiência-piloto do 20 Ciclo para as Aprendizagens. A portaria n. 285/2013 ratifica o parecer 225/2013 do CEDF, autorizando a organização em Ciclos para as Aprendizagens.

Depois de consolidar o BIA, a rede distrital ampliou, a partir do ano de 2013, a organização em Ciclos para as Aprendizagens, levando esta forma de organização da escolaridade para o segundo bloco do 2으 Ciclo: 4으 e 5음 anos do ensino fundamental. O amparo legal para ampliação gradativa dessa política pública foi logrado com a aprovação do Projeto de Organização Escolar em Ciclos para as Aprendizagens na Educação Infantil e Ensino Fundamental Anos Iniciais. A implantação foi gradativa e opcional por parte das unidades escolares da Rede Pública de Ensino do Distrito Federal (CEDF, 2014).

O parecer 251/2013 do CEDF aprovou o projeto de Organização Escolar em Ciclos para as Aprendizagens nos Anos Finais do Ensino Fundamental, que 
possibilitou a implantação gradativa e por adesão voluntária das instituições educacionais na Rede Pública de Ensino do Distrito Federal, autorizando "[...] a Organização Escolar em Ciclos para a Aprendizagem nos Anos Finais do Ensino Fundamental, na forma que se segue: 3을 Ciclo: Ensino Fundamental, do 6으 ao 9응 ano- 1ㅇ Bloco: 6ㅇ e 7음 anos;- 2o Bloco: 8o e 9o anos" (BRASíLIA, DF, 2013b, p. 3).

No ano letivo de 2013, cinco instituições da Rede Pública de Ensino do Distrito Federal que ofertavam Anos Finais do Ensino Fundamental com a organização em Ciclos para as Aprendizagens, numa experiência-piloto, tiveram seus atos escolares validados por meio do parecer 251/2013 do CEDF e pela portaria n. 304/2013, que o ratificou.

Em algumas unidades escolares, a organização escolar do 3으 Ciclo para as Aprendizagens foi implementada antes dos três anos mínimos para que a forma de organização em Ciclos para as Aprendizagens se tornasse obrigatória nas unidades escolares de Ensino Fundamental do Distrito Federal, conforme estabelece o PDE (2015-2024).

Das 386 unidades escolares que atendem anos iniciais, atualmente, 223 implantaram o $2^{\circ}$ ciclo, e das 210 unidades escolares que atentem aos anos finais, 15 implantaram o 3o ciclo. Algumas escolas já apresentam um ótimo trabalho pedagógico, servindo de modelos que têm sido utilizados por outras Unidades Escolares. (BRASÍLIA, DF, 2016, p. 11).

No ano de 2014, a portaria n. 206/2014, publicada no DODF n. 201/2014, em consonância com o parecer n. 158/2014 do CEDF, aprova as “Diretrizes Pedagógicas para a Organização Escolar do 2ㅇ Ciclo para as Aprendizagens, correspondente aos anos iniciais do ensino fundamental: Bloco Inicial de Alfabetização (BIA) e 20 Bloco (4ํe e 5a anos) da Rede Pública de Ensino do Distrito Federal" (BRASÍLIA, DF, 2014a). As diretrizes Pedagógicas do 2 o Ciclo para as Aprendizagens, de acordo com o parecer n. 158/2014, são propostas como documento orientador do trabalho pedagógico desenvolvido nos anos iniciais do ensino fundamental 2 Ciclo (BIA e 2으 Bloco - 4으 e 5으 anos), com base no Projeto de Organização Escolar em Ciclos para as Aprendizagens na Educação Infantil e Ensino Fundamental Anos Iniciais (CEDF, 2014). 


\section{IMPLANTAÇÃO DA ORGANIZAÇÃO ESCOLAR EM CICLOS NO DISTRITO FEDERAL E A FORMAÇÃO DOCENTE}

Em relação aos anos finais do Ensino Fundamental, a portaria n. 207/2014, também publicada no DODF n. 201/2014, em consonância com o parecer n. 159/2014 do CEDF, aprova as “Diretrizes Pedagógicas para a Organização Escolar do 3 Ciclo para as Aprendizagens, correspondente aos anos finais do Ensino

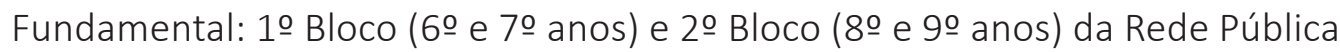
de Ensino do Distrito Federal" (BRASÍLIA, DF, 2014b, p. xx).

Essas diretrizes são flexíveis e, conforme o Parecer n. 159/2014-CEDF, é um

[...] documento orientador do trabalho pedagógico desenvolvido nos anos finais do ensino fundamental 3 o Ciclo, do 60 ao 9 o ano, em continuação aos 10 e 2 을 Ciclos, referentes à educação infantil e ao ensino fundamental, do Bloco Inicial de Alfabetização ao 50 ano, tendo em vista o Projeto Organização Escolar em Ciclos para as Aprendizagens nos Anos Finais do Ensino Fundamental, com implantação gradativa e por adesão das instituições educacionais, na Rede Pública de Ensino do Distrito Federal, aprovado pela Portaria no 304/SEDF/2013, com fulcro no Parecer no 251/2013-CEDF. (BRASÍLIA, DF, 2014b, s.p.).

Mesmo com todos esses aspectos legais, compreende-se que esse processo de organização escolar deve ser implementado com cautela, uma vez que a legislação é base dessa política pública, porém as leis não a sustentam por si só.

Assim, necessita-se compreender a política pública do terceiro ciclo para as aprendizagens, sabe-se que a utilização dos ciclos visa à superação do modelo tradicional de ensino que é excludente e seletista. [...]. É sabido ainda que a utilização das políticas públicas em âmbito educacional, se entendidas de forma equivocada, terão resultados de qualidade total e não de qualidade social, o que pode trazer consequências negativas a qualquer forma de organização. Ressalta-se ainda a necessidade de levar em consideração as experiências já consolidadas da organização escolar em ciclos. (CHAGAS; FERREIRA, 2018, p. 277-8).

Nessa perspectiva, Barretto e Mitrulis (2001) afirmam que essa forma de organização pedagógica está articulada a outros paradigmas que precisam ser considerados no momento de construção da proposta pedagógica, tais como a "[...] concepção de educação escolar obrigatória, desenho curricular, concepção de conhecimento e teoria de aprendizagem que fundamentam o ciclo, processo 
de avaliação, composição de turmas" (BARRETTO; MITRULIS, 2001, p. 102-4), ou seja, novos paradigmas de tempos e espaços de aprendizagens que são exigidos pela organização ciclada. E, ainda segundo as autoras, essa forma de organização escolar tem ganhado diversos adeptos, ou seja, muitas secretarias de educação que compreendem os ciclos como um ideário pedagógico os adotam como forma padrão de organização escolar.

Mesmo assim, a implementação dos ciclos não é uma política simples de ser recebida e compreendida pela comunidade escolar. Um dos primeiros obstáculos envolve um dos principais personagens do processo educacional: o docente que, na maioria das vezes, é arredio a um modelo de organização escolar que se opõem a seriação. Para Mainardes (2009), os profissionais que atuam na escola, no geral, não participam ativamente da construção da proposta em ciclos, o que prejudica a implementação desse modelo de organização escolar nas unidades educacionais, pois o profissional não terá, por exemplo, condições de discutir os fundamentos dessa organização, uma vez que não conhece ou não compreende teoricamente a proposta.

Para Ribeiro (2016), a organização escolar em ciclos não se resume em suprimir a retenção dos estudantes nas séries ou nos blocos; para a autora, os ciclos podem ser conceituados como uma nova concepção educacional, uma vez que apresentam razões ousadas na forma de organizar o ensino, que a difere da organização seriada. Contudo, em muitas secretarias, a "[...] supressão da reprovação é usada [...] simplesmente para maquiar estatísticas, não articuladas com uma vontade política de melhorar o atendimento escolar nem integrada a outras medidas com esse fim" (PARO, 2003, p. 51).

Assim, para que ocorra um processo de implementação com resultados satisfatórios, necessita-se de uma brusca ruptura com os paradigmas tradicionais de ensino, além de compreender a intenção da implementação dessa forma de organização nas secretarias de educação. Necessita-se, ainda, compreender as concepções que o docente tem sobre a organização do processo de ensino e aprendizagem. Vale ressaltar que "[...] a eliminação da reprovação como recurso didático apresenta-se [...] como exigência de um ensino de qualidade" (PARO, 2003, p. 51).

Segundo Mainardes (2009), os sistemas de ensino precisam questionar a lógica da escola tradicional, ou seja, rever sua estrutura, organização e finalidades. 
As limitações mais visíveis da escola graduada são os elevados índices de reprovação, a evasão escolar e os alunos em situação de distorção idade/ série com a reprovação e com o fracasso escolar e, por conseguinte, a sua transformação em um sistema educacional não-excludente e não-seletivo. (MAINARDES, 2009, p. 13, grifo do autor).

Segundo Mainardes (2009), a identidade docente está vinculada à escola seriada, ou seja, as experiências desse docente, no geral, têm raízes na escola de modelo tradicional de ensino. Os docentes que atuam nos sistemas de ensino (municipal, estadual e distrital) são oriundos de diversos tipos de formações, das mais tradicionais até, inclusive, as mais progressistas.

A chamada resistência dos professores aos ciclos tem sido um tema recorrente [...]. Embora a resistência seja um fato concreto entre os profissionais da educação, acreditamos que esta precisa ser compreendida no contexto no qual as políticas de organização escolar são implementadas. (MAINARDES, 2009, p. 56).

De qualquer forma, a resistência às formas de organização escolar mais flexível, como os Ciclos para as Aprendizagens, apresenta desconforto no exercício das funções do magistério a esses profissionais. Para Hoffmann (2008), as mudanças resultam sofrimento, uma vez que "[...] mudar de ideia dói mais do que trocar de pele. O professor precisa abandonar práticas seguras e conhecidas, arriscando-se a perder seu status de competência, seu controle sobre a situação, sua confiança no próximo passo" (HOFFMANN, 2008, p. 30).

Para Gatti (2013), é preocupante a atual formação dos professores nas licenciaturas para a atuação na educação básica; a autora discute que "A formação para a prática da alfabetização e iniciação à matemática e às ciências naturais e humanas é precária, como também é precária a formação para o trabalho docente nos anos finais do ensino fundamental e no ensino médio" (GATTI, 2013, p. 39). Essa formação precária nos cursos de licenciaturas agrava ainda mais a situação, pois essa formação traz insegurança ao futuro docente, que apresentará dificuldade no ato pedagógico.

Para Arroyo (1999), é possível superar a lógica tradicional, considerando a formação que os docentes já possuem, e "[...] assumir que a função de educador carrega dimensões definidas socialmente, a partir do que há de permanente nesses velhos papéis sociais. É outra lógica para a formação dos profissionais de educação básica" (ARROYO, 1999, p. 152). 
O autor afirma ainda que não se trata de colocar novas funções para serem treinadas, "[...] mas de criar situações coletivas que propiciem explicitar e cultivar o papel, os valores e saberes educativos que cada educador já põe em ação em sua prática, nas escolhas que faz cada dia no trato com os educandos" (ARROYO, 1999, p. 153).

A proposta de ciclos, na maioria das redes de ensino, não promove a devida ruptura com o tradicional, e sim reforça a lógica seriada, sendo apenas um amontoado de anos que servem para evitar a retenção, ou apenas postergar o inevitável, devido a algumas propostas de ciclos possibilitarem a retenção em determinados momentos do processo. Nesse contexto, Arroyo (1999) tem o seguinte posicionamento:

Se se pretende organizar a escola em ciclos, na visão tradicional se propõe que aprendam primeiro o que é ciclo, conteúdos de ciclos, avaliação de ciclo, passagem ou retenção no ciclo etc. Nessa visão tradicional, o profissional da educação básica é visto como alguém competente em tarefas, um tarefeiro [...], um prático. (ARROYO, 1999, p. 14-7).

De acordo com os estudos de Mainardes (2009), numa perspectiva de epistemologia geral, a Secretaria de Estado de Educação do DF, aderindo à organização escolar em Ciclos para as Aprendizagens, deve estar comprometida com a transformação do sistema educacional, dado que a organização ciclada vai ao encontro à lógica graduada, que é uma escola excludente e seletiva, além de questionar a estrutura, a organização e a finalidade dessas instituições educacionais. Nessa mesma linha de pensamento,

[...] a imagem cíclica não deve ser a circular, mas aquela que representada por uma espiral. A espiral contém em si o círculo, o ponto e a linha e, em um único movimento, sai e torna a si mesma, porém em um plano diferente. Havendo sempre uma transformação. É o fluir e o manter-se. O modo como pensamos a temporalidade do humano produz novas formas de perceber 0 mundo e de fazer políticas e pedagogias. (MELUCCI, 1991, apud BARBOSA, 2013, p. 75).

Segundo Barbosa (2013), a organização interna que compreende a forma de organização das turmas, a avaliação e o modo de conduzir o ensino são fatores que provocam o insucesso dos estudantes. Na tentativa de transformar essa realidade, os Ciclos para as Aprendizagens tornam-se uma alternativa. 
Barbosa (2013) ressalta que as escolas as quais introduziram a organização escolar em ciclos não necessariamente transformaram suas realidades, pois essa transformação é resultado das concepções de todos os envolvidos, e não será um decreto legislativo que transformará a realidade dessas instituições. A autora ressalta, ainda, que a sociedade é conservadora, priorizando manter relações assimétricas de poder e as questões de tradição, o que dificulta o redirecionamento das escolas que implementam os ciclos. E, sobre essa questão, Arroyo (1999) tem a seguinte afirmação:

é curioso constatar que é no campo da formação de profissionais de educação básica onde mais abundam as leis e os pareceres de conselho, os palpites fáceis de cada novo governante, das equipes técnicas, e até de agências de financiamento, nacionais e internacionais. [...] A forma como esse ofício é tratado nas políticas é como se fosse um fazer e pensar indefinido, deformado. (ARROYO, 1999, p. 151).

Nesse contexto, Hoffmann (2008) afirma que o poder público se preocupa com índices de acesso à escola pública, mas a qualidade é questionável. E outra questão levantada pela autora é a permanência desses estudantes nos sistemas, os quais são, na maioria das vezes, avaliados nos moldes tradicionais que ocorrem por meio de notas e conceitos, tornando-se um instrumento de exclusão, uma vez que são dados genéricos sem a devida preocupação com as necessidades pedagógicas dos estudantes. A autora sintetiza esse posicionamento da seguinte forma: "[...] muitos sabem que eles não sabem, mas não sabem o que não sabem e nem por que não sabem" (HOFFMANN, 2008, p. 91).

Já Freitas (2003) afirma que o modelo de organização em ciclos não pode ser imposto pelos sistemas de ensino, ou seja, não deve ser uma política pública que determine a utilização compulsória do modelo de organização pedagógica. Tendo por base experiências frutíferas, o autor afirma que uma opção seria a do convencimento por indução, assim, a gestão da escola teria autonomia para escolher o modelo pedagógico. Outrossim, "Não se deve fazer experimentos com redes inteiras" (FREITAS, 2003, p. 70). É importante ter claro o conceito de ciclos para implementação dessa política pública nos sistemas de ensino, por isso

[...] mais do que classificar as diferentes compreensões e possibilidades de implementar os ciclos, é importante caracterizar as concepções de educação e as políticas públicas que orientam as escolhas. A concepção de ciclos 
acaba sendo depositária dessas políticas e seu sucesso dependerá de tais concepções. (FREITAS, 2003, p. 72).

Nessa perspectiva, Gomes (2005) ressalta que, nas redes em que se implementaram os ciclos sem a devida preparação do corpo docente, o acolhimento desse modo de organização da escolaridade "[...] não chegou a ser equacionado do modo mais feliz, com a formação continuada requerida. Ao contrário, parece que se convocaram os soldados para uma guerra sem que eles estivessem preparados e convencidos da legitimidade desta" (p. 26). E, no que tange à questão curricular, muitos "[...] professores costumam dizer que o currículo 'vem de cima para baixo' e pouco resta a fazer em relação a isso" (SOUZA, 2008, p. 44).

Sabe-se que a formação continuada e a organização do trabalho pedagógico são elementos que estão intrinsecamente vinculados à forma de organização da escolaridade. E não seria diferente na organização da escolaridade em Ciclos para as Aprendizagens. Sabe-se ainda que ausência de investimento por parte do poder público nas unidades escolares é fator negativo nos resultados esperados (RIBEIRO, 2016).

Aliada à falta de investimento em formação docente, ainda há um deficit na formação inicial dos docentes nas diversas redes de ensino, e isso contribui para o insucesso de uma educação de qualidade social (GATTI, 2013).

A organização escolar seriada e a organização escolar em Ciclos para as Aprendizagens se aproximam enquanto propostas pedagógicas, visto que as práticas de ensino nas mais variadas formas de organização são bem próximas. Os estudos de Knoblauch (2003) apontam que, por mais que as secretarias de educação alterem a forma de organização, as práticas pedagógicas mesclam-se aos elementos tradicionais das propostas pedagógicas com os elementos inovadores, os quais são oriundos de novas formas de organização da escolaridade, como os Ciclos para as Aprendizagens.

\section{CONSIDERAÇÕES FINAIS}

A implementação do 3 Ciclo para as Aprendizagens está ocorrendo conforme os prazos estipulados pelo PDE (2015-2024), contudo a formação continuada em serviço para atender ao modelo de organização do 3으 Ciclo para as Aprendizagens necessita de maior empenho por parte da SEEDF. 
Ressalta-se que não é a forma de organização escolar que definirá o sucesso das aprendizagens. O que se pode colocar em voga é a aproximação da comunidade escolar diante de uma proposta pedagógica exequível, uma proposta que, seja ciclo, seja seriação, leve qualidade social aos estudantes, bem como qualidade de trabalho docente aos profissionais da educação.

Conclui-se afirmando que não há nada de errado como organização escolar em Ciclos para as Aprendizagens, já que é uma forma de organização que é utilizada pelos sistemas de ensino no Brasil, contudo, para que esse modelo de organização tenha resultados positivos, são necessárias ações antes, durante e depois da implementação da política pública. Pode-se ainda ressaltar que as unidades escolares, mesmo organizadas em Ciclos para as Aprendizagens, continuam utilizando estratégias de ensino que eram aplicadas na organização escolar seriada.

\section{REFERÊNCIAS}

ARROYO, M. G. Ciclos de desenvolvimento humano e formação de educadores. Educação \& Sociedade, Campinas, v. 20, n. 68, p. 143-62, 1999. Disponível em: www.scielo.br/pdf/ es/v20n68/a08v2068.pdf.Acesso em: 21 out. 2017.

BARBOSA, M. C. S. Infância, escola e uma nova compreensão da temporalidade. In: MOLL, Jaqueline (Org.). Os tempos da vida nos tempos da escola: construindo possibilidades. 2. ed. Porto Alegre: Penso, 2013.

BARRETTO, E. S. S.; MITRULIS, E. Trajetória e desafios dos ciclos escolares no país. Estudos avançados/USP, São Paulo, v. 15, n. 42, p. 103-40, maio/ago. 2001.

BRASÍLIA (Distrito Federal). Secretaria de Educação do Distrito Federal [SEEDF]. TiraDúvidas: Organização Escolar em Ciclos para as Aprendizagens - Ensino Fundamental. Brasília: SEEDF, 2016. Disponível em: http://www.cre.se.df.gov.br/ascom/documentos/ dez16/ens_fund_caderno_tira_duvidas_org_ciclos.pdf. Acesso em: 10 jul. 2018.

BRASÍLIA (Distrito Federal). Lei n. 5.499, de 14 de julho de 2015. PDE - Plano Distrital de Educação (2015-2024). Brasília, DF, 2015. Disponível em: http://www.cre.se.df.gov.br/ ascom/documentos/pde_15_24.pdf. Acesso em: 21 out. 2017.

BRASÍlIA (Distrito Federal). Portaria n. 206, de 24 de setembro de 2014. Aprova as Diretrizes Pedagógicas para a Organização Escolar do 20 Ciclo para as aprendizagens. Diário Oficial do Distrito Federal, Seção 01, p. 7, de 25 jul. 2014. Brasília-DF, 2014a. Disponível em: www.buriti.df.gov.br/ftp. Acesso em: 10 jul. 2018. 
BRASÍLIA (Distrito Federal). Portaria n. 207, de 24 de setembro de 2014. Aprova as Diretrizes Pedagógicas para a Organização Escolar do 3으 Ciclo para as aprendizagens. Diário Oficial do Distrito Federal, Seção 01, p. 7, 25 de jul. 2014. Brasília, DF, 2014b. Disponível em: www.buriti.df.gov.br/ftp. Acesso em: 1o jul. 2018.

BRASÍLIA (Distrito Federal). Parecer n. 225/2013-CEDF. Aprova o Projeto de Organização Escolar em Ciclos para as Aprendizagens na Educação Infantil e Ensino Fundamental Anos Iniciais. Brasília, DF, 2013. Diário Oficial do Distrito Federal, Seção 01, p. 13-14, de 5 dez. 2013. Brasília, DF, 2013a. Disponível em: www.buriti.df.gov.br/ftp. Acesso em: 29 jan. 2018.

BRASÍLIA (Distrito Federal). Parecer n. 251/2013-CEDF. Aprova o Projeto de Organização Escolar em Ciclos para as Aprendizagens nos Anos Finais do Ensino Fundamental. Brasília, DF, Diário Oficial do Distrito Federal, Seção 01, p. 3, 30 dez. 2013. Brasília, DF, 2013b. Disponível em: www.buriti.df.gov.br/ftp. Acesso em: 29 jan. 2018.

BRASÍLIA (Distrito Federal). Lei n. 3.483, de 25 de novembro de 2004. Amplia o Ensino Fundamental da Rede Pública de Ensino do Distrito Federal, de oito para nove anos de duração mínima. Brasília, DF, 2004. Disponível em:http://www.tc.df.gov.br/SINJ/ Norma/51417/Lei_3483_25_11_2004.html. Acesso em: 10 jul. 2018.

CHAGAS, A. M.; FERREIRA, V. A. A organização escolar em ciclos para as aprendizagens na Secretaria de Estado e Educação do Distrito Federal. In: CONGRESSO INTERNACIONAL DE EDUCAÇÃO: HISTÓRIA, HISTORIOGRAFIA, POLÍTICAS E PRÁTICAS, 2., Sorocaba, 2018. Anais [...]. Sorocaba, SP: Uniso, 2018. p. 262-80.

CONSELHO DE EDUCAÇÃO DO DISTRITO FEDERAL. Parecer $n$. 158/2014-CEDF. Aprova as Diretrizes Pedagógicas para a Organização Escolar do 2으 Ciclo para as aprendizagens, correspondente aos anos iniciais do ensino fundamental: BIA e 2을 Bloco (4은 5o anos) da Rede Pública de Ensino do Distrito Federal. Brasília, DF, 2014.

CONSELHO DE EDUCAÇÃO DO DISTRITO FEDERAL [CEDF]. Resolução n. 1/2012-CEDF, de 11 de setembro de 2012. Estabelece normas para o Sistema de Ensino do Distrito Federal, em observância às disposições da Lei n. 9.394, de 20 de dezembro de 1996- Lei de Diretrizes e Bases da Educação Nacional. Brasília, DF, 2012. Disponível em: http:// www.cre.se.df.gov.br/. Acesso em: 1ํ jul. 2018.

FREITAS, L. C. Ciclos, seriação e avaliação - confronto de lógicas. São Paulo: Editora Moderna, 2003.

GATTI, B. A. A formação inicial de professores para a educação básica: as licenciaturas. REVISTA USP, São Paulo, n. 100, p. 33-46, dez./fev. 2013. 
GOMES, C. A. Desseriação escolar: alternativa para o sucesso? Ensaio: Avaliação, Políticas Públicas Educacionais, Rio de Janeiro, v. 13, n. 46, p. 11-38, jan./mar. 2005.

HOFFMANN, J. Avaliar: respeitar primeiro, educar depois. Porto Alegre: Mediação, 2008.

KNOBLAUCH, A. Ciclos de aprendizagem e avaliação de alunos: novas práticas de registro, velhas intenções. In: REUNIÃO ANUAL DA ANPED, 26., Poços de Caldas, 2003.Anais [...]. Poços de Caldas: ANPED, 2003.

LIBÂNEO, J. C.; OLIVEIRA, J. F.; TOSCHI, M. S. Educação escolar: políticas, estrutura e organização. São Paulo: Cortez, 2012.

MAINARDES, J. A escola em ciclos: fundamentos e debates. São Paulo: Cortez, 2009.

MAINARDES, J. Reinterpretando os ciclos de aprendizagem. São Paulo: Cortez, 2007.

PARO, V. H. Reprovação escolar: renúncia à educação. 2. ed. São Paulo: Xamã, 2003.

RIBEIRO, M. M. L. Ciclos de aprendizagem e inovação pedagógica. Rio de Janeiro: Autografia, 2016.

SOUZA, R. F. Escola e sociedade. Curitiba: IESD Brasil S.A., 2008.

\section{Sobre os autores:}

Valdivina Alves Ferreira: Doutora em Educação (PUC GO), Mestre em Educação pela UFMS; Especialista em Planejamento Educacional, Métodos e Técnicas de Ensino, Ciência da Computação, Administração e Supervisão Escolar; Graduada em Pedagogia Licenciatura Plena pela FESURV. Docente no Programa de Pós-Graduação da Universidade Católica de Brasília (UCB). Líder do Grupo de Estudos e Pesquisas em Políticas Públicas Educacionais no Âmbito da Educação Básica (GEPPEB). Atua nos temas: Políticas Públicas Educacionais, Políticas Públicas de Educação Profissional e Tecnológica, Formação de Professores e Informática Educativa. E-mail: valdivina5784@hotmail.com, Orcid: http://orcid.org/0000-0002-2306-7465

Alisson Moura Chagas: Mestre em Educação pela Universidade Católica de Brasília (UCB). Atualmente, é Pedagogo-Orientador Educacional na Secretaria de Estado de Educação do Distrito Federal. Professor de Educação de Jovens e Adultos (EJA) na Secretaria Municipal de Santo Antônio do Descoberto. E-mail: 
alissonescola@gmail.com, Orcid: http://orcid.org/0000-0002-4063-9912

Thamara Maria de Souza: Mestre em Educação pela Universidade Católica de Brasília (UCB). Especialista em Gestão Pedagógica pela Pontifícia Universidade Católica do Paraná (PUCPR). Psicopedagoga clínica e institucional pela Universidade de Brasília (UnB). Especialista em Gestão de Recursos Humanos pela UCB (2007). E-mail: tmasouza@hotmail.com.br, Orcid: http://orcid.org/0000-0002-4483-7991

Recebido em: 26 de julho de 2019

Aprovado em: 28/03/2021 